\title{
Energy Diminution Methods in Green Cloud Computing
}

\author{
N.Thirupathi Rao ${ }^{1}$, Debnath Bhattacharyya ${ }^{2}$ \\ ${ }^{1,2}$ Department of Computer Science and Engineering, Vignan's Institute of \\ Information Technology (A), Visakhapatnam, AP, India \\ ${ }^{1}$ nakkathiru@gmail.com, ${ }^{2}$ debnathb@gmail.com
}

\begin{abstract}
Distributed computing center around the information figuring proficiency whereas green distributed computing is reasoning which depends on distributed computing design and concentrates on the vitality productivity of gadget and processing. Green Cloud Computing is an approach used to enhance the usage of figuring assets those are being utilized as part of the distributed computing system, for example, stockpiling, servers, its application, and benefits and decrease vitality utilization of these assets which enhances control proficiency. This is finished by different innovations like virtualization and virtual machines movement. This paper surveys the different systems purposed by the distinctive creators to make distributed computing more vitality proficient. The primary target of this paper is to think about and break down the idea of vitality proficient server farm engineering, asset allotment and streamlining.
\end{abstract}

Keywords: Cloud Computing, Energy efficiency, Virtualization.

\section{Introduction}

Distributed computing is a relevant virtualization idea for productive utilization of equipment and programming. It intends to furnish straightforwardness to its end clients with the assistance of on request [1][2]. In distributed computing assets (equipment or programming) are made accessible by at least one supplier. These assets can be utilized by various clients on the paid premise. These administrations gave by distributed computing are extensively groups for example, the Amazon, Sales drive, Microsoft, Google, IBM and Sun-Microsystems has set up numerous new server farms for facilitating cloud applications, business application, the gaming entryway, the media content conveyance and logical preparing. For running these server farms an enormous measure of vitality is required [3]. Power is required for screens, comfort, arrange peripherals, cooling devotees of the processor and cooling framework [4]. In spite of the fact that distributed computing give money related advantages, however its influence utilization and carbon outflow has turned into a noteworthy natural concern. Server farms store substantial measure of information in the cloud and vast measure of vitality is squandered as warmth on cloud. Cloud has turned out to be one of the real sources to an unnatural weather change in view of numerous an Earth-wide temperature boost gases like carbon dioxide, carbon monoxide, and so on are discharged amid the power age process.

Green figuring is characterized as domain maintainable processing. Green processing productively deals with its assets by keeping condition at focus. The fundamental goal of green figuring is to build the vitality productivity and lessen $\mathrm{CO} 2$ discharge. The analysts have given

Article history:

Received (May 18, 2019), Review Result (September 2, 2019), Accepted (October 5, 2019) 
an assortment of programming and equipment answers for the issue of vitality proficiency in cloud operation by limiting the effect of distributed computing on the earth. Virtualization innovation can be utilized to show signs of improvement asset separation and less vitality utilization through live movement and combination. The analysts recommend three sorts of answers for making distributed computing green distributed computing that is the condition neighborly. To begin with arrangements programming enhancement, second equipment streamlining and third is organize improvement.

\section{POWER SAVING APPROACHES}

Vitality utilization and execution of the framework rely upon numerous elements. Some straightforward procedures give the fundamental vitality administration servers in Cloud situations. Different systems for sparing vitality incorporate utilization of virtualization strategies for better asset use [5]. Different specialists have put numerous endeavors to decrease the vitality utilization in mists and server farms. In this part we display the most recent research endeavors by the specialist that endeavor to manage them. One of the methods that are as a rule ordinarily utilized as part of cloud condition is virtualization. The task of numerous VMs helps in solidifying the errand and killing other physical machines by bringing down the utilization of vitality. Live movement alludes to moving virtual machines starting with one physical server then onto the next straightforwardly.

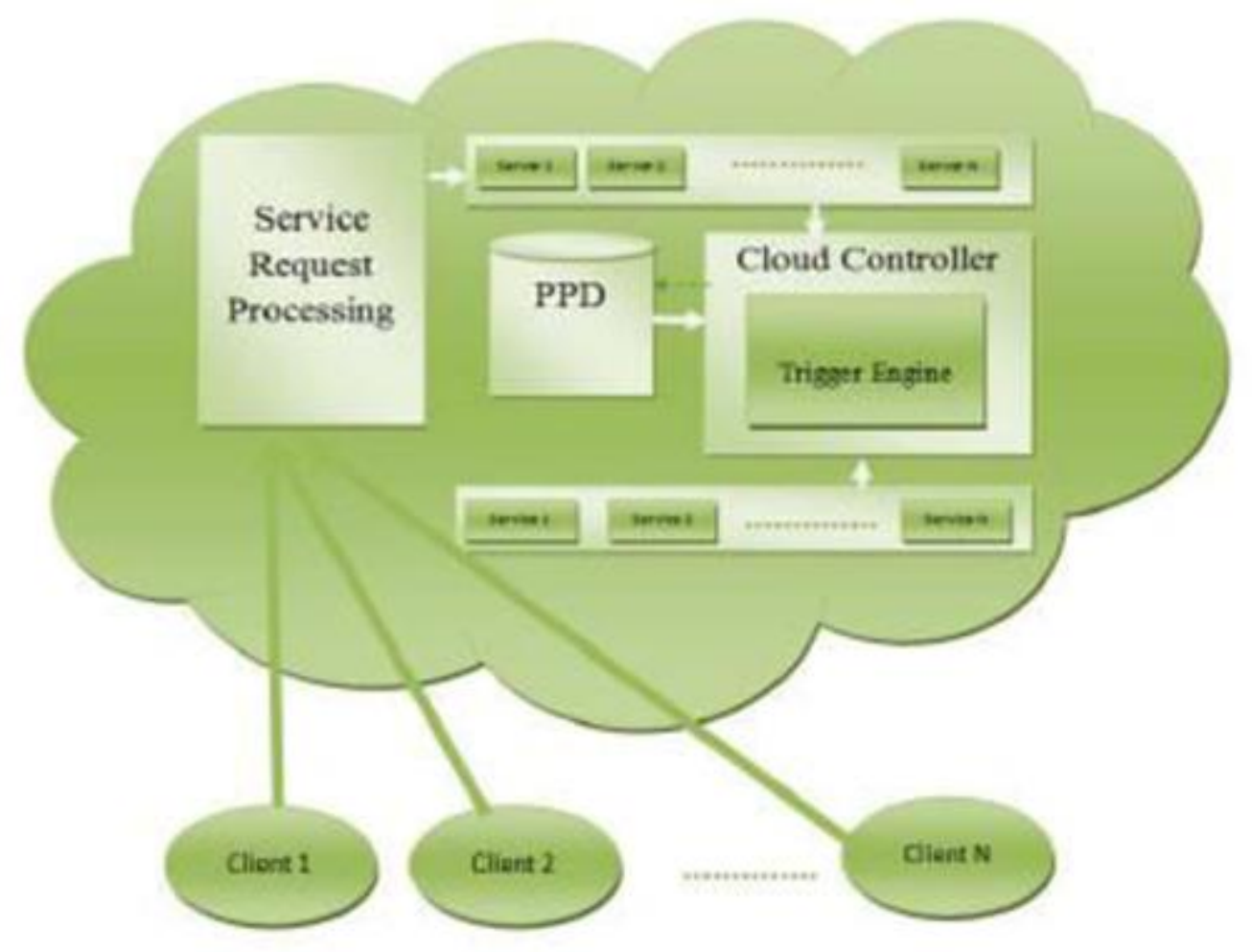

Figure. 1 Green computing approaches model [20]

The relocation of virtual machines is observed to be a valuable procedure for making frameworks more vitality productive. VMM should be possible by utilizing a distinctive calculation like first fit, Monte Carlo, Round Robin and so forth [6]. The significant system being utilized as part of virtual machine relocation is Pre-Copy. As of late, fundamental web 
firms have influenced gigantic information to focus to enable their online business. Before processing power essentially centered around centralized servers set a way out of sight choices aside from a substantial measure of computational power [7][8][9].

Also, the use of switches is as the take after, 17\% assigned for center switches, half for get to switches and $34 \%$ for accumulation switches. Besides, $15 \%$ of aggregate power use is utilized by the center and total switches together [10]. Coincidentally, as indicated by the necessities for arrange execution, correspondence quality and load adjusting, the discernible alternative to pick is to save the conglomeration and center switches in a disseminated way. The server farm arranges considers for the distinctions among control utilization levels of different server farm outlines [11][12][13][14]. The 3-Tire with fast (3Ths) organize incorporates less center and conglomeration switches. In addition, the openness of $100 \mathrm{G}$ joins includes some significant downfalls of augmentation per-switch control use. It is reasoned that a 3Tier system expends under 3Ths system [15]. Figure 1 speaks to a normal circulation of vitality utilization of a 3T server farm. This paper inspected numerous techniques for vitality sparing in server farms for distributed computing and it talks about different methodologies proposed in past research works in this field [16].

\section{VITAL ECONOMY RESOLUTIONS FOR THE NETWORK}

System foundation is the following principle vitality shopper in server farms. Around $30 \%$ of the whole vitality utilization which used for calculation is devoured by server farm arrange [16][17]. System in Data Centers incorporates switches and interfaces[18][19]. The creators expressed that power utilization relies upon limit of the connection rather than its use. In addition, scientists delineated that vitality utilization of switches depends on an advertiser and it is coordinated with the quantity of line cards and ports included. It ought to be viewed as that power utilization of the two connections and switches are vital for diminishing force utilization by arrange. The four after arrangements are existed for sparing vitality in server farm systems,

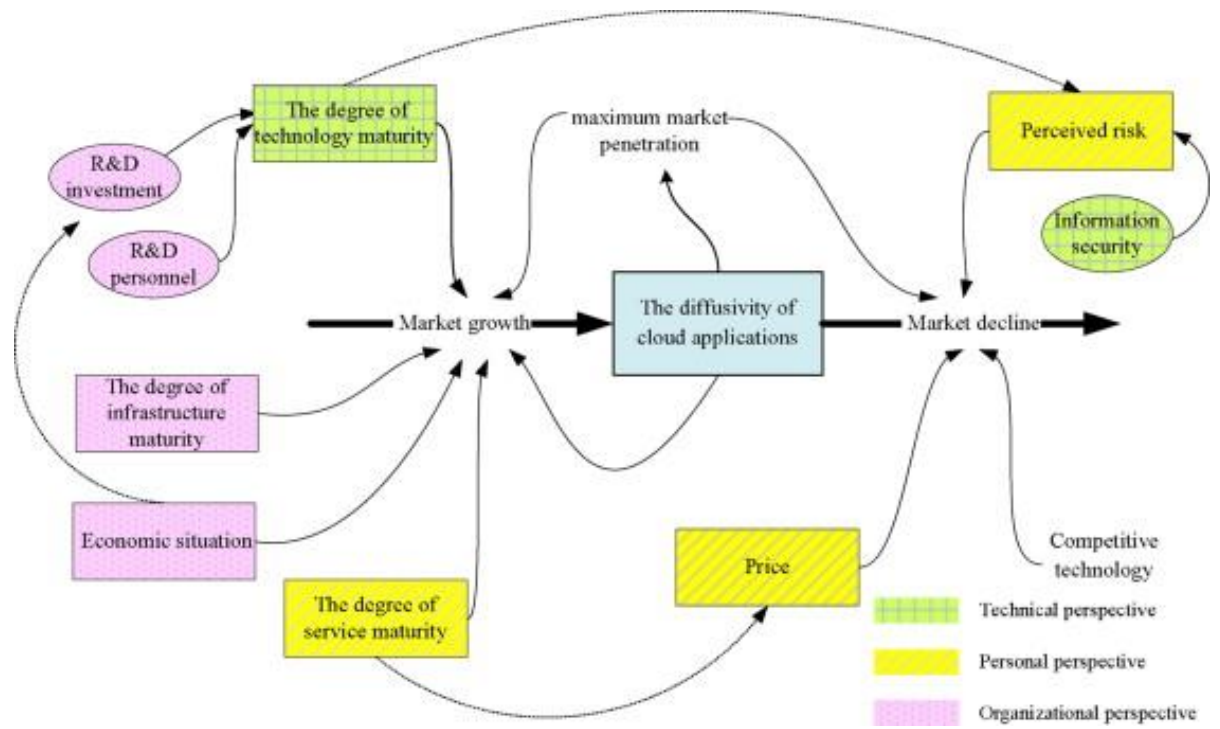

Figure 2. Economy technology models in cloud computing [21]

Versatile Link Rate strategy is broadly considered on wired systems [20]. Notwithstanding, it has not been utilized on the server farm arranges yet. This approach depends on the possibility 
that vitality utilization of a connection might be diminished its information rate, while movement heap of system joins are low much of the time. In such cases, Adaptive Link Rate diminishes connect vitality use by progressively setting join information rate to its use, while rest mode strategy diminishes vitality use through turning off system assets or putting them to rest mode. In addition, other dynamic system assets should meet QoS prerequisites. Virtual system implanting is the following methodology which is valuable for lessening vitality utilization of system [21]. VNE is for the most part helpful while the system activity is low. The points of system virtualization are to utilize inserting calculations to dole out virtual system assets on a less number of physical framework with an ideal approach[20]. The sit out of gear organize assets could be turned off or put into rest mode.

As of now, Energy mindful steering or green directing for diminishing vitality utilization in server farm arrange is considered [13]. The fundamental thought of Energy mindful directing is to convey steering administration to less number of system assets to decrease vitality use, while supporting system execution. As of late, blended methodologies for sparing vitality in server farms are proposed widely. Mahadevan et al. [14] expressed that lone $16 \%$ of energy utilization might be spared by affecting system vitality diminishing approaches alone. It merits specifying that by consolidating server and system vital good techniques, vitality could be set aside $75 \%$ of vitality use in server farms. By joining vitality sparing methodology, arrange movement union and server workload combination are helpfully utilized. Mahadevan et al. [14] recommends three strategies for sparing vitality in server farms:

NTC diminishes vitality use extensively by evacuating all repetition in the system. This approach solidifies movement on few quantities of connections and switches, and sit without moving connections and switches are deactivated. SLC is an approach to merge organizes activity in a less connections and changes to enable the controller to kill unused assets. To accomplish this objective, SLC exchanges employments to few quantities of servers to kill unused servers. The specialists assessed these three systems on a genuine Web 2.0 contextual investigation in a genuine server farm. The outcomes show that $16 \%$ of vitality could be put away by executing just a connection state adjustment approach, $75 \%$ of vitality could be put away by actualizing both server stack combination and system activity solidification together.

\section{POWER ECONOMY BY RENEWABLE POWER BASIS}

Nowadays, stresses over expanding vitality utilization have coordinated to social advantages in controlling the vitality use. Accomplished arrangements comprise of the joining of sustainable power source server farm [5], Yahoo's New York server farm [6][7], Google server farms [8], and Microsoft server farms [9]. A sorption chiller influences the cooling framework to work by utilizing the warm vitality which recouped from the server farm parts and supplemental sun oriented vitality [3]. It is prescribed to utilize additional vitality, if accessible, from elective recovery frameworks, mostly the sun based vitality, while losing the rest of the vitality from the server farms isn't sufficient to switch on the cooling frameworks. To accomplish a similar reason, the geothermal power and distinctive elective vitality sources can be utilized. To get the cooling unit while the warmth vitality assimilated from the servers isn't sufficient, a two-overlap framework is offered to warm the wet necessary for the ingestion chiller, utilizing sun powered power designing or additional obtainable reestablishing heat source [3]. 


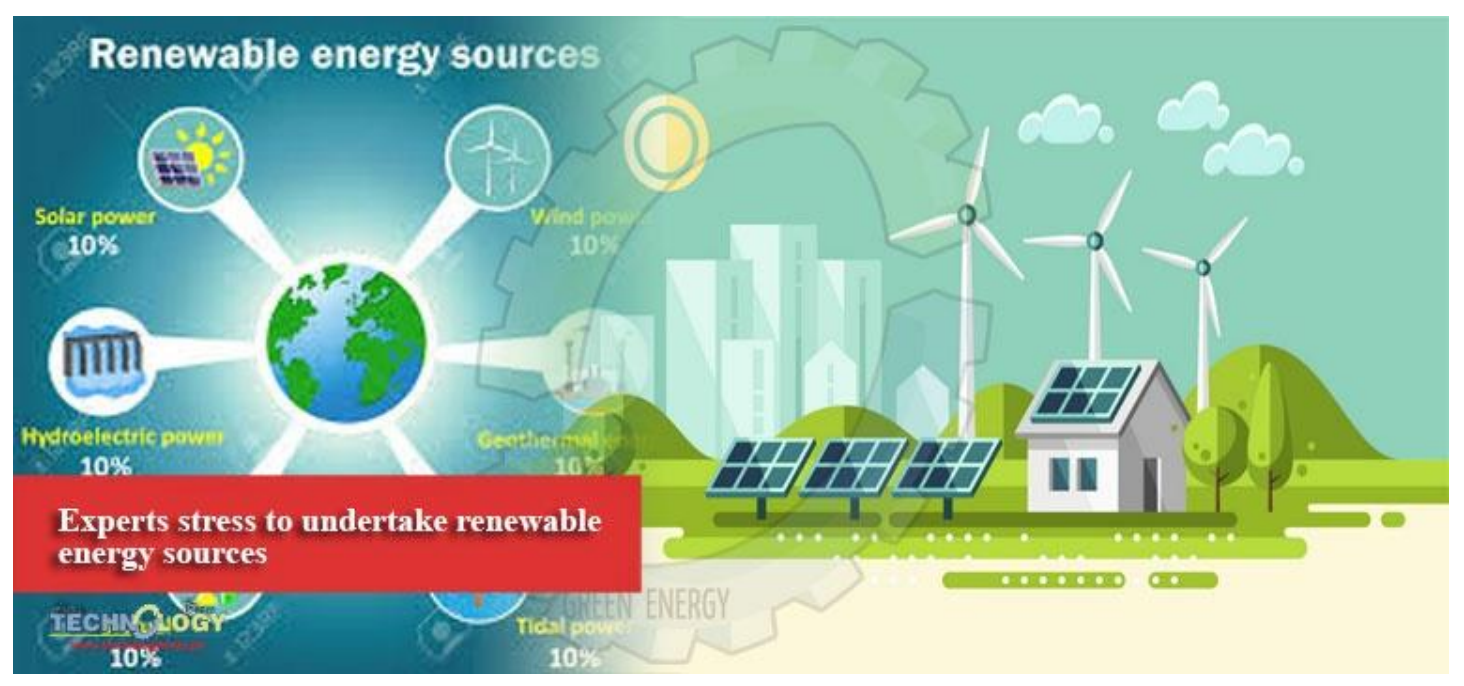

Figure 3. Renewable energy sources model [22]

\subsection{EXISTING POWER RESOURCEFUL METHODS CONCENTRATING ON SERVER AND NETWORK}

This strategy actualizes activity union and VM to spare vitality in server farm systems. In any case, repetition prerequisites counteract killing inert hubs and virtual machine position in organize. In this way, Honey guide proposed as an answer for sidestep connects to scale up the measure of system switches. Along these lines button can be killed under the terms of repetition. Honey guide is actualized for fattree topology and utilizes the primary fit calculation to find VM. VMs are isolated into a progression of gatherings where general activity between the gatherings is limited while general movement of inside gathering is expanded. System activity aggregated into fewer courses to put the remaining system segments into rest mode for lessening vitality utilization.

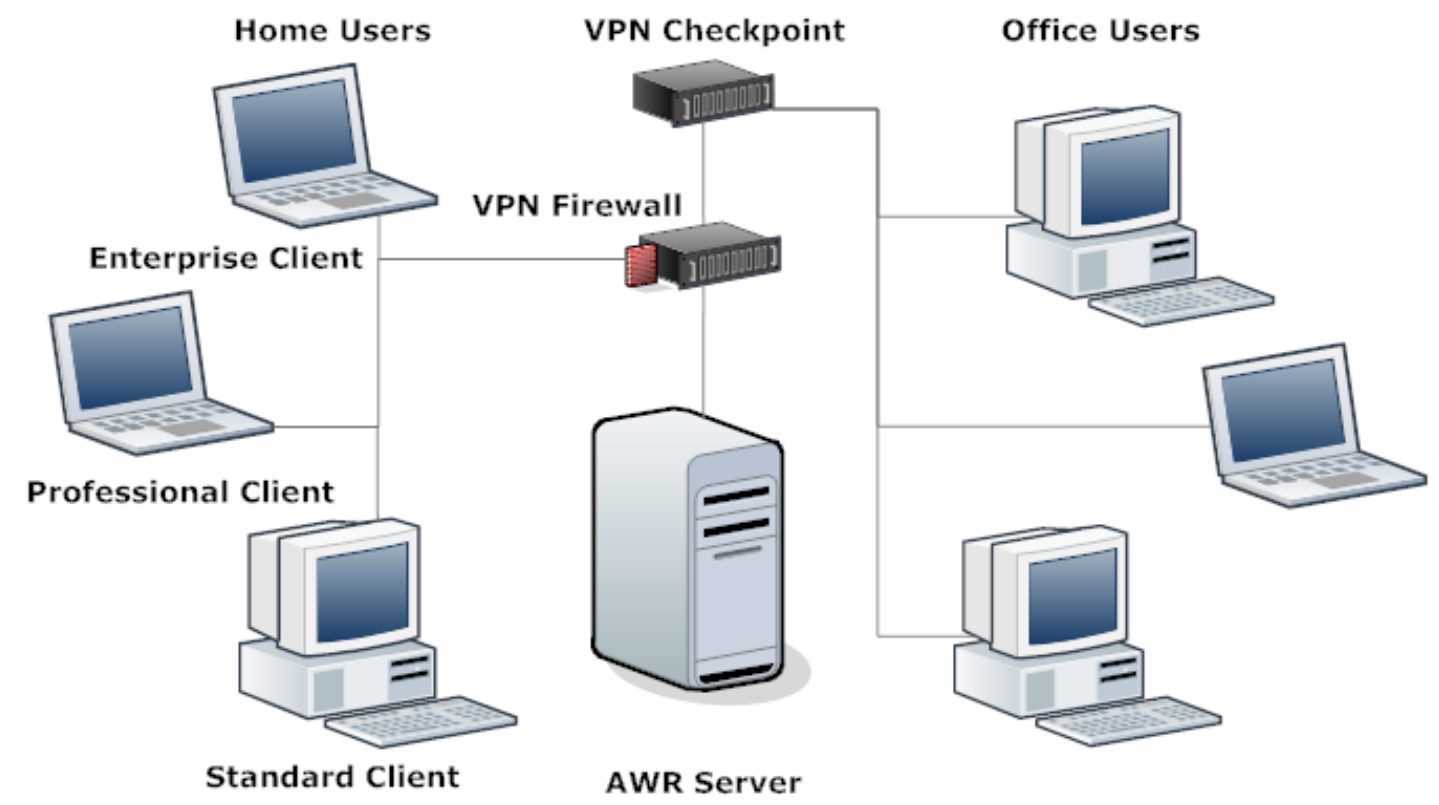




\section{Figure. 4 Server and network model [23]}

An engineering system was produced by Beloglazov et al. [3] for sparing vitality in dim compute. In light of this examination, specialists offered vitality distribution heuristics arrangement for server farm parts to expand vitality sparing in server farms. This examination has assessed the vitality asset designation calculations utilizing the solidification of Virtual Machines powerfully. Specialists planned this test system to get the data about vitality devoured through server farm components like servers, switches, and interfaces. The aftereffects of reenactment decided the viability of utilizing power administration composition like shutdown arranges components powerfully, recurrence scaling and voltage scaling [16]

The authors utilized the energy of processing hubs on/off as the vitality sparing strategies in their examination. The fundamental thought behind this examination is to indicate the ideal measure of physical hubs, modify the suitable recurrence to every one of the hubs and to assess the aggregate recurrence of CPU basic to display the required reaction time. As indicated by the optical burst changing innovation to limit undertaking consummation times, Koseoglu and Karasan [6] have applied a comparative technique for joining the distribution of system ways and computational assets in Grid situations. The aftereffects of recreation picked up for 2-level, 3-level and 3-tire with rapid server farm structures that play out the test system adequacy in utilizing different power organization pattern, similar to dynamic shutdown, recurrence scaling and voltage scaling.

\section{CONCLUSIONS}

The paper begins by presenting the idea of distributed computing, green registering and afterward the different procedures by which Information innovation is moving towards Green IT. A proficient and successful utilization of processing assets in cloud influence it To green Cloud registering, Some methodologies examined in this paper utilize workload designation and planning and disjoin profiling without utilization of virtualization others make utilization of virtualization system. Decreasing carbon discharge and vitality utilization distributed computing server farms make an open test and arrange toward making green server farms. A viable and effective utilization of figuring assets in cloud can help in accomplishing Green Cloud Computing. Be that as it may, because of expanding request on transmission capacity and system availability of server farm, vitality utilization of server farm system and server farm servers and system will quickly develop later on. This paper introduces the vast majority of the innovations utilized for vitality sparing in server farms and examines different methodologies proposed in past research works in this field. The investigation uncovers that there are numerous vitality proficient structures for distributed computing and server farms that make distributed computing Green distributed computing.

\section{References}

[1] Masanet, E.; Shehabi, A.; Ramakrishnan, L.; Liang, J.; Ma, X.; Walker, B.; Hendrix, V.; Mantha, P. The Energy Efficiency Potential of Cloud-Based Software: A U.S. Case Study. 2013. Available online: https://www.osti.gov/scitech/servlets/purl/1171159 (accessed on 08 October (2018).

[2] Laura Diana Raudu “Green cloud computing: A literature review", Symmetry, Vol.9, no.295, (2017).

[3] Rasheed, H. Data and infrastructure security auditing in cloud computing environments. Int. J. Inf. Manag. (2014), 34, 364-368.DOI: 10.1016/j.ijinfomgt.2013.11.002

[4] Rabkin, A.; Stoica, I.; et al. Above the Clouds a Berkeley View of Cloud Computing. 2009. Available online: http://cacs.usc.edu/education/cs653/Armbrust-CloudComp-Berkeley09.pdf (accessed on 14 June (2016). 
[5] Youseff, L.; Butrico, M.; Da Silva, D. Toward a Unified Ontology of Cloud Computing. In Proceedings of the Grid Computing Environments Workshop, Austin, TX, USA, 12-16 November 2008; IEEE: New York, NY, USA, (2008); pp. 1-10.

[6] Heininger, R. IT Service Management in a Cloud Environment: A Literature Review. In Proceedings of the 9th Workshop on Information Systems and Services Sciences, München, Germany, 8-10 May (2012); pp. 1-12.

[7] Mell, P.; Grance, T. The NIST Definition of Cloud Computing. 2009. Available online: http://nvlpubs.nist. gov/nistpubs/Legacy/SP/nistspecialpublication800-145.pdf [Last accessed on 14 June (2019)].

[8] Buyya, R.; Yeo, C.S.; Venugopal, S.; Broberg, J.; Brandic, Y. Cloud computing and emerging IT platforms: Vision, hype, and reality for delivering computing as the 5th utility. Future Generation Computer Systems, (2009), Vol.25, pp.599-616. DOI: 10.1016/j.future.2008.12.001

[9] Kliazovich, D.; Bouvry, P.; Khan, S.U. GreenCloud: A packet-level simulator of energy-aware cloud computing data centers. J. Supercomput. (2012), Vol.62, pp.1263-1283.

[10] Liu, L.; Wang, H.; Liu, X.; Jin, X.; He, W.B.; Wang, Q.; Chen, Y. GreenCloud: A new architecture for green data center. In Proceedings of the 6th International Conference Industry Session on Autonomic Computing and Communications Industry Session, Barcelona, Spain, 15-19 June (2009); ACM: New York, NY, USA, 2009; pp. 29-38.

[11] Apple. (2012). Apple Facilities Environmental Footprint Report. Available: http://www.apple.com/environment/reports/do cs/Apple_Facilities_Report_2013.pdf. [Last accessed on 14 June (2016)].

[12] Gandhi, M. Harchol-Balter, R. Das, and C. Lefurgy, "Optimal power allocation in server farms," in ACM SIGMETRICS Performance Evaluation Review, (2009), pp. 157-168.

[13] R. V. Aroca and L. M. G. Goncalves, "Towards green data centers: A comparison of x 86 and ARM architectures power efficiency," Journal of Parallel and Distributed Computing, vol. 72, pp. 1770- 1780, 2012.DOI: 10.1016/j.jpdc.2012.08.005

[14] C. Guo, G. Lu, H. J. Wang, S. Yang, C. Kong, P. Sun, et al., "Secondnet: a data center network virtualization architecture with bandwidth guarantees," in Proceedings of the 6th International COnference, (2010), pp. 15.DOI: $10.1145 / 1921168.1921188$

[15] J. Torres, D. Carrera, K. Hogan, R. Gavalda, V. Beltran, and N. Poggi, "Reducing wasted resources to help achieve green data centers," in Parallel and Distributed Processing, 2008. IPDPS 2008. IEEE International Symposium on, (2008), pp. 1-8.DOI: 10.1109/IPDPS.2008.4536219

[16] R. Subrata, A. Y. Zomaya, and B. Landfeldt, "Cooperative power-aware scheduling in grid computing environments," Journal of Parallel and Distributed Computing, vol. 70, pp. 84-91, (2010).

[17] https://www.google.com/search?q=green+cloud+computing\&source=lnms\&tbm=isch\&sa=X\&ved=0ahUKE wi-q9nSt5LgAhXHdn0KHTN0DXkQ_AUIDigB\&biw=1366\&bih=657\#imgrc=ieKmaelgFvTRHM. [Last accessed on 25-01-(2019)]

[18] https://www.google.com/search?q=green+cloud+computing\&source=lnms\&tbm=isch \&sa=X\&ved=0ahUKE wi-q9nSt5LgAhXHdn0KHTN0DXkQ_AUIDigB\&biw=1366\&bih=657\#imgrc=xFllwUWyksx35M. [Last accessed on 25-01-(2019)]

[19] https://www.google.com/search?biw=1366\&bih=608\&tbm=isch\&sa=1\&ei=O_xPXJuSAsv68QXEizg\&q=ren ewable+green+cloud+computing\&oq=renewable+green+cloud+computing\&gs_l=img.3...196149.197878..19 8167...0.0..2.503.2633.0j4j2j0j1j2.....1....1..gws-wiz-img.L8JZe0Log44\#imgrc=Eg7MKgWj_Q8niM. [Last accessed on 25-01-(2019)]

[20] A blog written by Sumati Manchanda on "Scrutinizing Various Approaches towards Green Cloud Computing" on 2014. [Last Accessed on 10, June, (2019)]

[21] Juin Ming TSui et . al., "A novel model of technology diffusion: System dynamics perspective for cloud computing", Journal of Engineering and Technology Management, Vol.33, (2014), pp.47-62.DOI: 10.1016/j.jengtecman.2014.02.003 
Energy Diminution Methods in Green Cloud Computing

[22] A blog written by Sayyed Shehzer Abbas entitled "Experts stress to undertake renewable energy sources". [Last Accessed on 10, June, (2019)]

[23] An Article written by Aura Dozescu at Advanced Web Ranking entitled "How to Improve Your Company Workflow with Advanced Web Ranking Server”, 2011. [Last Accessed on 10, June, (2019)] 